\title{
Effect of Spondias dulcis Leaves Infusion on Glucose Transport Rate through Rat Intestine Epithelium Cell Membrane
}

\author{
Krisna Destia, ${ }^{1}$ Anna Martiana, ${ }^{2}$ Sylvia Rachmayati ${ }^{3}$ \\ ${ }^{1}$ Faculty of Medicine Universitas Padjadjaran, ${ }^{2}$ Department of Biochemistry Faculty of Medicine \\ Universitas Padjadjaran, ${ }^{3}$ Department of Clinical Pathology Faculty of Medicine Universitas \\ Padjadjaran/Dr. Hasan Sadikin General Hospital, Bandung
}

\begin{abstract}
Background: Nowadays, people consume herbal remedies made from plants which are believed to be able to relieve certain symptoms and restore normal metabolic functions. Golden apple (Spondias dulcis) leaf has the potential to lower blood glucose. The purpose of this experiment was to observe the anti-hyperglycemic effect of S. dulcisleaves infusion on glucose transport rate through intestinal mucosal membrane of Wistar rats.

Methods: An experimental study was conducted from October 2013 to November 2014. Nine male Wistar rats were selected aged 12-16 weeks, weighted 250-400 grams, healthy, actively moving, and had never been used in experiments. The rats were anesthetized, cut open and given three kinds of treatments: three kinds of glucose solutions were flowed through the intestinal tract using in situ perfusion method. Samples obtained from the rat's intestine were measured with a spectrophotometer to obtain glucose rate transported through intestinal membrane from every treatment. The results of condition 1 and 2 , and condition 1 and 3 were then compared.

Results: The means of glucose transported through rat intestines epithelium cell membrane were $6.43 \mathrm{mg} /$ $\mathrm{dl}, 9.40 \mathrm{mg} / \mathrm{dl}$ and $9.81 \mathrm{mg} / \mathrm{dl}$. Statistic test result showed there was no significant difference on the glucose transported in every treatment.

Conclusions: Glucose absorption rate in rat intestine doesnot decrease after they are given S. dulcis leaves infusion. Therefore, this experiment concludes that S. dulcis leaves do not affect the glucose transport rate in rat intestines epithelium cell membrane. [AM].2016;3(4):562-5]
\end{abstract}

Keywords: Antihyperglycemic effect, glucose transport rate, Spondias dulcis leaves.

\section{Introduction}

For centuries, people consume herbal remedies made from plants which are believed to have certain effects that are able to relieve certain symptoms and restore normal metabolic functions and balance. ${ }^{1}$ Besides the nutritional values, herbs also have low toxicity and economic feasibility. In the last few decades the demand in studies of plants has increased due to people's awareness of the benefits.

Golden apple (Spondias dulcis Forst. syn. or SpondiascythereaSonn.) is a native plant in Melanesia and Polynesia. Although commonly used as a food source, it is also used as a remedy for diarrhea, eye infection, ${ }^{2}$ itchiness, ${ }^{3}$ sore throat, antidote, and internal ulceration.
A study concluded $S$. dulcis contains a lot of phytochemicals with many pharmacological activities. One function of $S$. dulcis less explored is as an antihyperglycemic agent. The photochemical responsible for the effect is thought to be flavonoid. ${ }^{4}$

Flavonoid is a chemical substance commonly found in plants which are known to have an antihyperglycemic effect. The mechanism of action is by inhibiting sodium-glucose linked transporter 1 (SGLT1), protein transporter of intestinal membrane which plays a role in the active transport of glucose ${ }^{5,6}$ By inhibiting glucose entering the bloodstream, the glucose in the blood is used first without the additional glucose from food intake and therefore lowers the blood glucose level.

An invitro study in 2010 has proved

Correspondence: Krisna Destia, Faculty of Medicine, Universitas Padjadjaran, Jalan Raya Bandung-Sumedang Km.21, Jatinangor, Sumedang, Indonesia, Phone: +6281573871018 Email: krisna.destia@gmail.com 
thatleaves of the plant have shown antihyperglycemic activity. However, there are no further studies to ensure the effect on living organisms. Therefore, an insitu experiment using Wistar rats as the objects was conducted. The purpose of this experiment was to observe the antihyperglycemic effect of S. dulcisleaves on glucose transport rate through Wistar rats' intestinal mucosal membrane.

This study might be a model and early step for future experiments regarding the development of herbal remedies for treating hyperglycemia patients, or even a prevention of people with risk factors from developing hyperglycemia.

\section{Methods}

This study was a laboratory experimental study, performed during the period of October 2013 to November 2014. The experiment itself was held at the Biochemistry Laboratory, Universitas Padjadjaran and reviewed by the Health Research Ethics Committee, Faculty of Medicine Universitas Padjadjaran.

The objects used were male Wistar rats aged 12-16 weeks, weighted 250-400 grams, healthy and actively moving, and have not been used in any other experiments. The rats were under observation for three months and conditioned with dark/light cycle, and enough space and ventilation. They were fasted overnight for 9 hours before the experiment was conducted the next day. The sample size was calculated using Federer formula. From these criteria, 9 rats were selected to be used in the experiment.
The leaves were obtained from theSpondiasdulcis tree at Cinangka Village, Ujungberung. Seven youngest leaves were selected from the sprout. Next they were cut into small pieces, and then were added into an infusion pot containing aquadest with 1:1 ratio, and boiled for 15 minutes to create an infusion.

Furthermore, an experimental type of study was conducted since the data for glucose transport rate influenced by theS. dulcis leaves infusion were not available, and by doing the experiment we could observe and obtain the samples firsthand. This study used in situ perfusion method which enabled the intestine to function normally for 6-8 hours. $^{7}$

The overnight fasted rats receivedKetamin $0.4 \mathrm{ml}$ by intramuscularanesthetic injection route. After half an hour, a rat was fixated onto a board. The abdomen was sterilized using an alcohol swab before cut open to gain access to their intestines. Then a cannula was inserted at $10 \mathrm{~cm}$ under pylorus and another one at $25 \mathrm{~cm}$ from the first site. The intestine underwent three times washing of $\mathrm{NaCl} 0.9 \%$ and blowing. Then the cannulas were attached to the perfusion machine by elastic tubes.

Moreover, three kinds of treatments were executed: a $25 \mathrm{ml}$ glucose solution was flowed for 60 minutes, a $25 \mathrm{ml}$ glucose solution mixed with $1 \mathrm{ml} \mathrm{S}$. dulcis leaves infusion for the next 60 minutes, and $25 \mathrm{ml}$ glucose for the last 60 minutes. Between each treatment, the intestine underwent three times washing and blowing. As a result,1 ml samples were obtained from the rat intestine every fifteen minutes at 0 th, 15 th, 30th, 45th, and 60th minute.

Table Means of glucose

\begin{tabular}{cccc}
\hline Rat & Solution I (mg/dl) & Solution II (mg/dl) & Solution III (mg/dl) \\
\hline 1 & 1.84 & 16.67 & 8.52 \\
2 & 7.72 & 2.94 & 14.34 \\
4 & 2.69 & 10.04 & 12.12 \\
5 & 10.57 & 9.14 & 8.29 \\
6 & 1.61 & 6.87 & 5.99 \\
7 & 11.32 & 10.14 & 11.32 \\
8 & 10.57 & 11.10 & 5.98 \\
9 & 7.72 & 10.12 & 14.34 \\
Means & 3.82 & 7.54 & 7.40 \\
Note: Solution I: glucose solution (mg/dl), solution II: glucose solution and S. dulcis infusion (mg/dl), solution III: \\
glucose solution (mg/dl).
\end{tabular}


The measurement of glucose samples was performed by using the reagent kit. Trichloroacetic acid (TCA) $8.0 \%$ was used to deproteinize the samples, then they were centrifuged at $3000 \mathrm{rpm}$ for 10 minutes. The supernatant was mixed with the glucose reagent and incubated in water at $37^{\circ} \mathrm{C}$ for 10 minutes. The absorbance rate of the sample was read using a spectrophotometer at 500 $\mathrm{nm}$ wavelength. The results of each treatment were then compared to know the effect of $S$. dulcis leaves on glucose transport rate in the rat intestine epithelium cell membrane.

The data distribution was checked using the normality test Kolmogorov-Smirnov and homogeneity test, and was analyzed by the Analysis of Variance (ANOVA) test using statistic software. The data distribution and homogeneity were considered normal if p-value> 0.05 . The result of ANOVA was considered statistically significant if the p-value $<0.05{ }^{8}$

\section{Results}

The means of glucose transport rate of solution I (glucose solution), solution II (glucose solution and S. dulcis infusion), and solution III (glucose solution) were $6.43 \mathrm{mg} / \mathrm{dl}, 9.40$ $\mathrm{mg} / \mathrm{dl}$, and $9.81 \mathrm{mg} / \mathrm{dl}$ (Table 1).

After the data of glucose absorbance was obtained, the results were analyzed using statistic software. The Kolmogorov-Smirnov test showed that p-values of solution I, II and III were $0.906,0.819$ and 0.832 . The test of Homogeneity of Variances also showed that $\mathrm{p}$-valuewas 0.505. The ANOVA test showed thatp-valuewas 0.125 .

\section{Discussions}

After the data of glucose absorbance was obtained, the results were analyzed using statistic software. Kolmogorov-Smirnov test was used because the normality test result showed p-valuesof solution I, II and III were $0.906,0.819$ and 0.832 ( $p$-value>0.05) meaning that the distribution of the data was normal. The test of Homogeneity of Variances also showed p-valuewas 0.505 (p-value > 0.05) which informed us of the homogeneity of the data.

The ANOVA test was used to test the significance of the means of the glucose transport rate. The result showed p-value was 0.125 ( $p$-value> 0.05) meaning that the result was not significant statistically, or that the effect of $S$. dulcis was not significant to the glucose transport rate through the intestinal membrane.

The result from the analysis showed there was no statistically significant difference between the glucose transport rate in solution I and II. This result is different with the result of the in-vitro experiment from 2010. This may happen because of a few possibilities which are: (a) flavonoid is highly metabolized, which alters the structure and the antihyperglycemic capacity; ${ }^{9}$ (b) as flavonoid enters the body, it is recognized as a strange substance and modified in order to be excreted through urine or bile; ${ }^{9}$ (c) the antihyperglycemic effect of $S$. dulcis works on other processes of glucose metabolism;10 (d) the antihyperglycemic effect of S. dulcis is only effective after prolonged treatment; and/or there were human errors on the data collection, such as faulty reading in reagent mixing or in spectrophotometer results.

There was also no statistical difference between glucose transport rate in solution I and III, meaning that the effect of $S$. dulcis was reversible. This result may happen because the effect will be permanent only after long-term exposure, or that the effect is really temporary and only appears with the consumption.

From this experiment, it can be concluded that $S$. dulcis does not have any significant effect on the glucose transport rate through intestinal mucosal membrane. Further studies are still needed to know the antihyperglycemic mechanism of $S$. dulcis.

This study had limitations which were: the experiment used only one type of dose; it also did not explore other things such as effective dose of $S$. dulcis for human consumption.

With this conclusion, other experiments should be conducted with several different doses of S.dulcis to discover the effective doses of S. dulcis.Another suggestion is to use alcohol instead of aquadest to pull the flavonoid content out of the leaves, since $S$. dulcis is an alkaloid.

\section{References}

1. Sumngern C, Azeredo Z, Subgranon R, Matos E, Kijjoa A. The perception of the benefits of herbal medicine consumption among the Thai elderly. J Nutr Heath Aging. 2011;15(1):59-63.

2. Rahmatullah $M$, Ferdausi D, Mollik MAH, Azam MNK, Rahman M, Jahan R. Ethnomedicinal survey of Bheramara area in Kushtia district, Bangladesh. Am 
Eurasian J Sustain Agric. 2009;3(3):53441.

3. Rahmatullah M, Ferdausi D, Mollik A, Jahan R, Chowdhury M, Haque W. A survey of medicinal plants used by kavirajes of chalna area, Khulna district, Bangladesh. Afr J Tradit Complement Alter Med. 2010;7(2):91-7.

4. Islam SMA, Ahmed KT, Manik, Wahid MA, Kamal CSI. A comparative study of the antioxidant, antimicrobial, cytotoxic and thrombolytic potential of the fruits and leaves of Spondias dulcis. Asian Pac J Trop Biomed. 2013;3(9):682-91.

5. Drozdowski LA, Thomson AB. Intestinal sugar transport. World J Gastroenterol. 2006;12(11):1657-70.

6. Wright EM, Hirayama BA, Loo DF. Active sugar transport in health and disease. J
Intern Med. 2007;261(1):32-43.

7. Volpe DA. Application of method suitability for drug permeability classification. AAPS J. 2010;12(4):670-8.

8. Dahlan S. Statistik untuk kedokteran dan kesehatan. $3^{\text {rd }}$ ed. Jakarta: Penerbit Salemba Medika; 2008.

9. de la Rosa LA, Alvarez-Parilla E, Gonzalez-Aguilar GA. Fruit and vegetable phytochemicals: chemistry, nutritional value and stability. New Jersey: Wiley; 2009.

10. Pamunuwa G, Karunaratne D.N, Waisundara V.Y. Antidiabetic Properties, Bioactive Constituents, and Other Therapeutic Effects of Scoparia dulcis. Evid Based Complement Alternad Med.2016; 2016(0):8243215. 